\title{
INFLUENCE OF OXYGEN AND CARBON DIOXIDE CONCENTRATIONS ON THE RESPIRATION OF TOMATO FRUITS ${ }^{1}$
}

\author{
Felix G. Gustafson
}

As A part of a general study of the physiological activities of tomato fruits the writer has conducted some experiments with a view of finding out what effect $\mathrm{O}_{2}$ and $\mathrm{CO}_{2}$ tensions have on the respiratory activities of these fruits. Sando (1920) noted that tomatoes picked green and wrapped in paper had a higher acid content and a lower sugar content than fruit ripened on the vines. Evidently the lack of aeration influenced the chemical activities during the ripening process. He did not, however, study the respiratory activities of these fruits.

There have been several investigations in which the effects of $\mathrm{O}_{2}$ and $\mathrm{CO}_{2}$ tensions upon respiratory activities of other plants have been studied. A brief summary of these experiments will be given, however, leaving out the experiments dealing with fungi.

Stich (1891) conducted some rather extensive experiments with small fruits, flowers, seedlings, and seeds in which he varied the oxygen concentration of the atmosphere surrounding the plant material. The oxygen concentration was reduced by the introduction of hydrogen into a gasometer to replace part of the air. Respiration was measured by the amount of $\mathrm{CO}$. produced. The concentration of oxygen needed by different plants to carry on their normal rate of respiration varied considerably. The concentration which brought about a reduction in $\mathrm{CO}_{2}$ production ranged from less than 1 per cent in seeds of peas to 5.5 per cent in seedlings of oats. Nearly half the plants studied showed no reduction in amount of $\mathrm{CO}_{2}$ released in an atmosphere of 2 per cent $\mathrm{O}_{2 .}$. Seedlings were unusually tolerant, while flower buds as a whole were the least tolerant. No controls were 11 sed.

Fidd and West $(1928,1931,1933)$ of the Low Temperature Research Station, Cambridge, England, have made several investigations on the influence of O. tension upon the rate of respiration of fruits. They have found that in pears at a temperature of $1 \circ \mathrm{C}$. the $\mathrm{CO}_{2}$ production is reduced only slightly at 5 per cent $\mathrm{O}_{2}$ and to about half the normal rate at an $O_{2}$, tension of 2 to 1 per cent. At $10^{\circ} \mathrm{C}$. they found that a 5 per cent $O$, concentration decreased the respiration to one-half the normal rate. Bananas at the same temperature were not influenced by a decrease of 0 ., to 5 per cent, and even concentrations as low as 2.5 to 0.1 per cent had an appreciable effect only after several days. They state that pears when confined to an atmosphere of 100 per cent $O$. first increased their $\mathrm{CO}_{2}$ output above the control but later the $\mathrm{CO}_{2}$ production ceased entirely, while the controls actually showed an increase.

1 Received for publication December 10, 1935.

Paper from the Department of Botany of the University of Michigan, No. 553.
Parija (1928) has shown that at a temperature of $22^{\circ} \mathrm{C}$. the rate of respiration of apples decreases even at $O$, tensions as high as 9 per cent.

Chevillard et al. (1930) found that the oxygen consumption begins to decrease at a much higher $O_{\text {, }}$ tension than does the CO. production. Thus in the moss, Hypnum triquetrum, the oxygen consumption is only about 87 per cent of normal at 15 per cent $\mathrm{O}_{2}$ tension, while the $\mathrm{CO}_{2,}$ production is not influenced until the $\mathrm{O}_{2}$ of the atmosphere has been reduced to about 4 per cent. Much the same is true of potato tubers. In leaves of cress and in carrot roots both the $\mathrm{O}_{2}$ consumption and $\mathrm{CO}_{2}$ production are influenced to about the same extent by the $O_{2}$ tension, but the respiration begins to decrease in the cress at an $O_{2}$ tension of 16 per cent, while there is no decrease in the carrots until the $\mathrm{O}_{2}$ tension is around 7 per cent. This difference in influence which $O_{y}$ concentration exerts upon the $\mathrm{O}_{2}$, consumption and $\mathrm{CO}$. production is very interesting, as it indicates that anaerobic respiration may take place even in quite high concentrations of $\mathrm{O}$..

In the aforementioned investigations the $\mathrm{CO}_{2}$ concentration has remained very low and there has therefore been no effect produced by it. In an investigation on the effect of $\mathrm{CO}$, upon various physiological processes in plants Kidd (1916) also studied the influence of $\mathrm{CO}$, upon respiration. He found that when the initial $\mathrm{CO}_{2}$, concentration was 10 per cent and $\mathrm{O}_{2}, 20$ per cent there was a decrease in $\mathrm{CO}$. production in white mustard and green pea seed below that of the same seeds when in normal air. The temperature was $25.5^{\circ} \mathrm{C}$. Most of the experiments lasted 40 hours, but even when the time was only 14 to 24 hours there was a decrease in respiration. Willaman and Beaumont (1928) found that when apple twigs were kept in a respiration chamber without aspiration the rate of $\mathrm{CO}$, production was lower than when air was continually drawn through the chamber. The $\mathrm{CO}_{2}$ and $\mathrm{O}_{2}$ concentrations in the chamber were not stated, but from the fact that they had a large amount of material in the chamber and the duration of the experiment was sometimes quite extended, one may assume that considerable $\mathrm{CO}$. had accumulated and that the $\mathrm{O}_{2}$ tension was quite low.

Only Willaman and Beaumont's experiments were conducted under conditions similar to those of the writer in that as the $\mathrm{O}$, was decreasing the $\mathrm{CO}$, was increasing in the atmosphere around the plants. These conditions are, of course, the same as those met with under storage or transportation of fruits.

Procedure.-The writer's experiments with tomatoes were conducted during all seasons of the year. The plants were grown in the greenhouse and out of doors, so the results can be considered as being repre- 

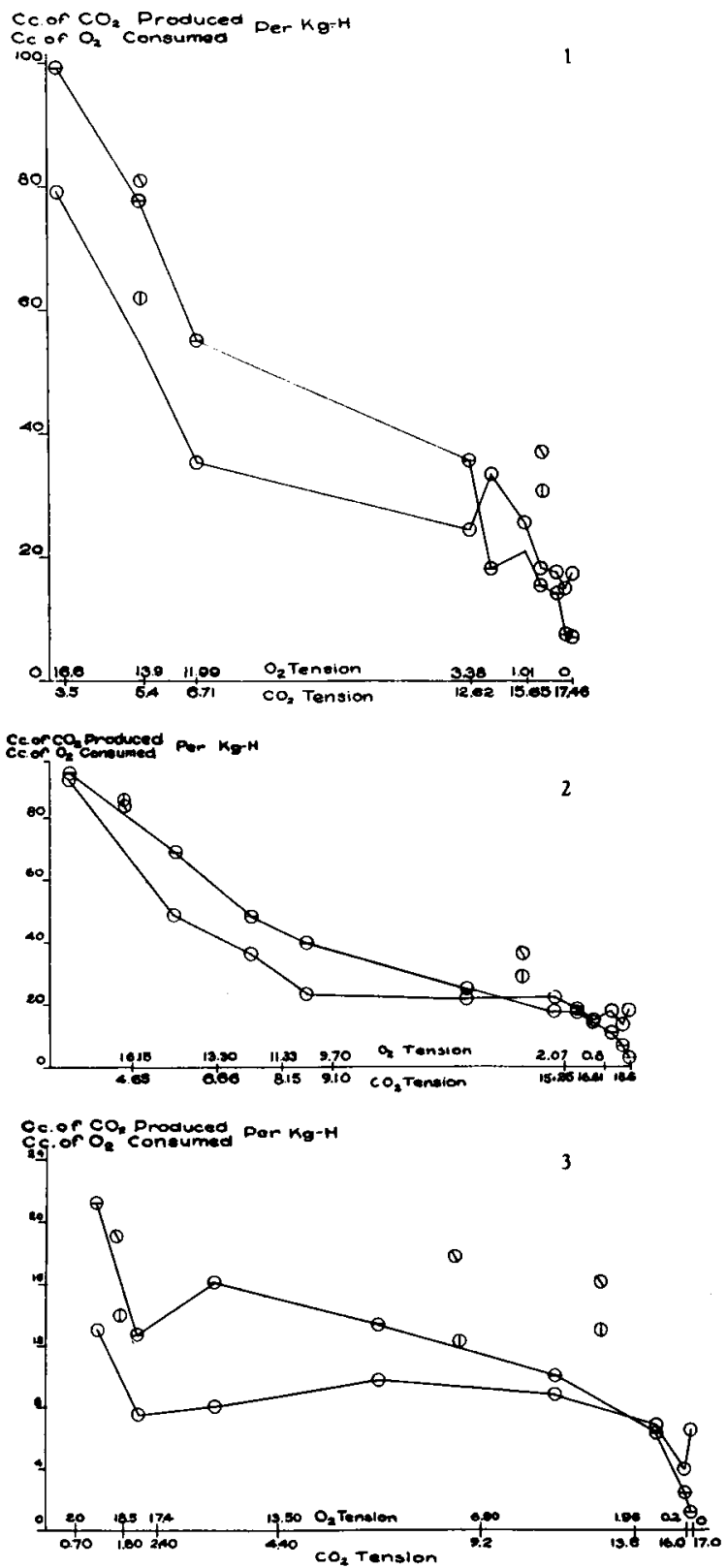

Figure 1. Respiratory activity of small (1.64 to 2.18 $\mathrm{cm}$.) green tomato fruits at $16^{\circ}-18^{\circ} \mathrm{C}$. in a closed container, when, as designated by the abscissa, the $O_{2}$ was decreasing and the $\mathrm{CO}_{2}$ increasing in concentration. The plain circles denote the $\mathrm{CO}$. production and the circles with horizontal lines the $O_{2}$ consumption. A control of similar fruits in normal air was run at the same time and the activity of these is denoted at corresponding times, by circles with perpendicular lines for $\mathrm{CO}_{2}$ production and circles with slanting lines for $\mathrm{O}_{2}$ consumption. It must be noted that while the data for the experimental fruits rejresent a relation between respiratory activity and $\mathrm{O}_{2}-\mathrm{CO}_{2}$ concentrations, the control expresses a relation between respiratory acivity and time. Even though the bringing together in the same graph of these two different relations may be somewhat confusing, it is done to show what the experimental fruits would sentative of the variety used, namely, John Baer, under several growing conditions.

The fruits were picked from the greenhouse or the field as needed, and as soon as they could be brought to the laboratory were placed in the dark, constant temperature room where the experiment was to be conducted. The time interval between placing the fruits in the dark room and first sampling varied somewhat. If the fruits were taken directly from the warm greenhouse into the warm temperature room, about 2 to 3 hours were allowed to elapse. When the fruits from the warm greenhouse were placed in the cold room or when fruits were brought from the field in the fall into the warm room, a 5-hour interval was allowed to bring the fruits into equilibrium with the temperature of the experimental room.

The experiments were carried out at two temperature ranges. The lower temperature varied from $15^{\circ}$ to $18^{\circ} \mathrm{C}$. and the higher from $30^{\circ}$ to $35^{\circ} \mathrm{C}$. This does not mean that there was a variation of $5^{\circ}$ in a single experiment, but that some experiments were carried out at a temperature of $15^{\circ}$ to $17^{\circ}$, others from $16^{\circ}$ to $18^{\circ}$, etc. The temperature fluctuated about $2^{\circ}$ in the lower range and less than $1^{\circ}$ at the higher.

The fruits whose respiration was studied were enclosed, during the experiment, in glass bottles sealed with rubber stoppers. The size of the bottles used varied from about 4 to 6 liters. During the experiment the air in the bottle was continuously stirred by a device marle for the purpose. Samples of gas were taken at intervals ranging from three to twentyfour hours, depending upon the rate of respiration. The analysis of these samples gave the $\mathrm{O}_{2}$ and $\mathrm{CO}$. tensions to which the fruits were exposed as well a: the rate of respiration. As the experiment progressed, the $\mathrm{O}_{2}$, tension became less and the $\mathrm{CO}_{2}$ greater. If the experiment lasted several days and numerous samples had been taken, the pressure in the bottle was reduced below atmospheric pressure. To avoid this, the bottle was connected with the outside air at intervals. This necessitated a new analysis of the enclosed air, as even a slight inflow of air was sufficient to change its composition. The control fruits

have done if they had not been confined. The experiment was completed in 24 hours.

Figure 2. Respiratory activity of green fruits 2.15 to $2.80 \mathrm{~cm}$. in diameter at $15^{\circ}-17^{\circ} \mathrm{C}$. in a closed container. Plain circles represent $\mathrm{CO}_{2}$ production and circles with horizontal lines $\mathrm{O}_{2}$ consumption. Circles with perpendicular lines represent $\mathrm{CO}_{2}$ production and circles with slanting lines $O$ s consumption of similar control fruits at corresponding times. For further explanation see figure 1. The experiment lasted 23 hours.

Figure 3. Respiratory activity of green fruits 4.62 to $5.90 \mathrm{~cm}$. in diameter at $15^{\circ}-17^{\circ} \mathrm{C}$. in a closed container. Plain circles represent $\mathrm{CO}_{2}$ production and circles with horizontal lines $O_{2}$ consumption. Circles with perpendicular lines represent $\mathrm{CO}_{2}$ production and circles with slanting lines $O_{2}$ consumption of similar control fruits at corresponding times. For further explanation see figure 1. The experiment lasted 4 days. 

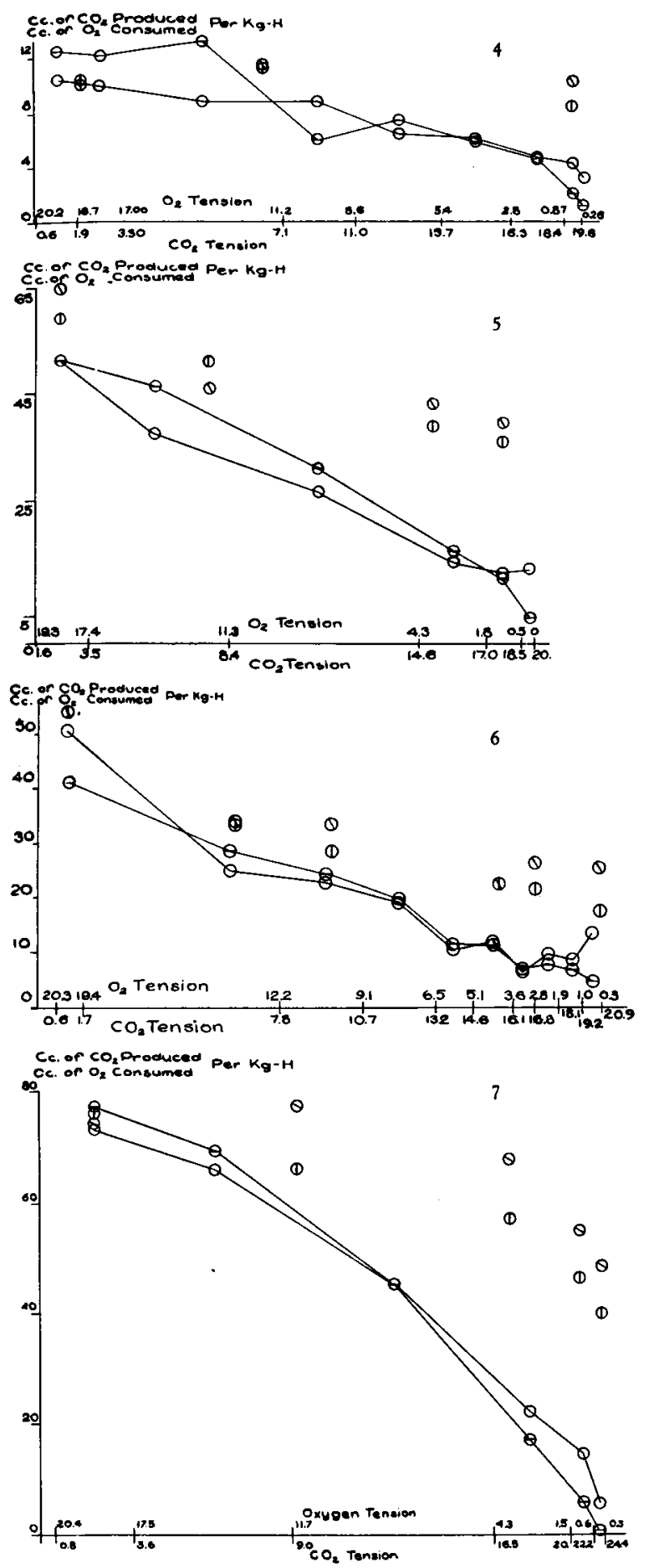

Figure 4. Respiratory activity of ripe fruits at $15^{\circ}-$ $17^{\circ} \mathrm{C}$. in a closed container. Plain circles represent $\mathrm{CO}_{2}$ production and circles with horizontal lines $\mathrm{O}_{2}$ consumption. Circles with perpendicular lines represent $\mathrm{CO}_{2}$ production and circles with slanting lines $\mathrm{O}_{2}$ consumption of similar control fruits at corresponding times. For further explanation see figure 1. This experiment was conducted for 5 days. were in the respiration chambers only during the seven or eight hours each day when their respiratory rate was heing determined. During the remaining time they were on a shelf in the constant temperature room to insure that they were exposed to a high $O_{2}$ tension.

The gas andyes were made with a HendersonHaldane pipette. Details of analysis, sampling, etc. can be obtained from a paper on microbic respiration by Nory, Rochm, and Soule (1925). At the beginning of each experiment, a few minutes after the bottle had been closed, a sample of air was drawn from the bottle and analyzed. This procedure gave much more constant results than when no initial analysis was made, because, as had been discovered from a few preliminary analyes, the laboratory air was not constant from day to day, especially as far as the $\mathrm{CO}_{2}$ content was concerned.

Discussion of REsults.-Preliminary experiments, though conducted without proper controls, showed very definitely that the oxygen tension influenced the rate of both $\mathrm{CO}_{2}$ production and $\mathrm{O}_{2}$ consumption. Later experiments were carefully controlled.

To show graphically the influence of a gradual decrease in $\mathrm{O}_{2}$ tension and an increase in the $\mathrm{CO}$, tension upon the respiration of tomatoes at temperature $15^{\circ}$ to $18^{\circ} \mathrm{C}$., four experiments with controls have been chosen. These four experiments were made with fruits ranging in size from $1.6 \mathrm{~cm}$. to full-grown and mature. The respiratory activity has been plotted against $\mathrm{O}$, and $\mathrm{CO}$, tensions of the atmosphere surrounding the fruits; and the respiration of the control fruits in normal atmosphere has been indicated by points at corresponding times without reference to the abscissae, so that the controls are really represented by time curves.

Figure 1 represents an experiment conducted with very small fruits $(1.60$ to $2.18 \mathrm{~cm}$. in diameter) grown

Figure 5. Respiratory activity of green fruits averaging in diameter $4.6 \mathrm{~cm}$, at $34^{\circ}-35^{\circ} \mathrm{C}$, in a closed container. Plain circles denote $\mathrm{CO}_{2}$ production and circles with horizontal lines $\mathrm{O}_{2}$ consumption. Circles with perpendicular lines denote $\mathrm{CO}_{2}$ production and circles with slanting lines $\mathrm{O}_{\mathrm{g}}$ consumption at corresponding times. The experiment lasted 4 days. For further explanation see figure 1 .

Figure 6. Respiratory activity of green fruits, averaging in diameter $5.16 \mathrm{~cm}$, at $30^{\circ}-31^{\circ} \mathrm{C}$. in a closed vessel. Plain circles denote $\mathrm{CO}_{2}$ production and circles with horizontal lines $\mathrm{O}_{2}$ consumption. Circles with perpendicular lines represent $\mathrm{CO}_{2}$ production and circles with slanting lines $O_{2}$ consumption of similar control fruits at corresponding times. The experiment lasted 10 days. For further explanation see figure 1.

Figure 7. Respiratory activity of ripening fruits at $30^{\circ} \mathrm{C}$. in a closed vessel. Plain circles represent $\mathrm{CO}_{2}$ production and circles with horizontal lines $\mathrm{O}_{2}$ consumption. Circles with perpendicular lines represent CO. production and circles with slanting lines $\mathrm{O}_{2}$ consumption of similar control fruits at corresponding times. The experiment lasted 5 days. For further explanation see figure 1 . 
out of doors. For the experiment 125 fruits were used while 50 were used for the control. The temperature varied from $16^{\circ}$ to $18^{\circ} \mathrm{C}$. The experiment lasted only 33 hours, which probably reduced the starvation effects somewhat. Until the $\mathrm{O}_{2}$ tension reached about 3 per cent, there was no appreciable difference between the two lots; but at this concentration the $\mathrm{O}_{2}$ consumption, which had been greater than the $\mathrm{CO}_{2}$ production, became less in the experimental fruits. There was also a slightly greater decrease in $\mathrm{CO}_{2}$ production than at the higher concentration.

Another experiment in which somewhat larger fruits (2.15 to $2.80 \mathrm{~cm}$. in diameter) were used is represented by figure 2 . There is no essential difference between this experiment and the preceding one.

In experiments 50 and 51 (fig. 3) the fruits were full grown (average $5.2 \mathrm{~cm}$. in diameter) but as yet showing no ripening except a slight decrease in the amount of chlorophyll; however, by the end of the experiments several fruits had turned faintly pink. In these experiments there was no appreciable decrease in the respiratory rate of the control, while in the experimental fruits there was considerable decrease in $\mathrm{CO}_{2}$ production after the $\mathrm{O}_{2}$ tension had reached a value of 3.5 per cent. The $\mathrm{O}_{2}$ consumption began to decrease considerably earlier and continued to fall quite rapidly after 1 per cent had been reacherl.

Ripe fruits were used in experiments 46 and 47 (fig. 4). In these experiments there was again practically no decrease in the control. The $\mathrm{CO}$, production decreased in amount quite gradually in the experimental fruits, but the total decrease was, however, considerable,-from 10.4 cc. to $3.3 \mathrm{cc}$. per $\mathrm{Kg}-\mathrm{H}$. As usual the $O$, consumption decreased more than the $\mathrm{CO}_{2}$ production, but here also the decrease was quite gradual until the $\mathrm{O}_{2}$ tension had renched a value of about 2 per cent, when the decrease became much greater.

In the first two of the four experiments cited, where the fruits were very small, the rate of decrease in respiration was approximately the same in the controls as in the experimental fruits, except for the more rapid decrease in the $O$, consumption at the end of the experimental fruits. It is very possible that in these small, actively growing and rapidly respiring fruits the depletion of the available foods was a much more important factor than lack of $O$... In the larger green or mature fruits, where the food supply is more ample and the respiration is much slower, the lack of $O$, is shown to be an important factor. Here there is no decrease in respiration in the controls, probably due to ample respiratory material, while the decrease begins to show quite early in the experimental fruits. The writer does not mean that the young fruits are not influenced by low $O$. tension, but that its effect is so much less than that of starvation that it is masked by the latter.

The experiments at the higher temperature are not so complete as at the lower. The smallest fruits used were $4.6 \mathrm{~cm}$. in diameter and these, illustrated by figure 5, show a gradual decrease in respiration as $\mathrm{O}_{2}$ is consumed, which, however, is considerably greater than that in the control. In experiment 35 (fig. 6) somewhat larger green fruits were used. This experiment, which lasted ten days, is peculiar in that the $O$, consumed is almost the same in amount as the $\mathrm{CO}_{2}$ produced, except at the beginning and the end when more $\mathrm{CO}_{2}$ is produced. The decrease is considerably greater when $\mathrm{O}_{2}$ is diminished than when it remains around 19 to 20 per cent. In the last experiment (fig. 7) at the higher temperature ripening fruits were used. This shows the most striking difference between the behavior of the experimental and control fruits. This is, no doubt, due to the ripening processes actively taking place. It is also to be noted that the $\mathrm{O}_{2}$ concentration at which the $\mathrm{O} .2$ consumption becomes less than the $\mathrm{CO}$. production is much greater than in any other experiment.

All these experiments demonstrate more or less clearly that when the $\mathrm{O}_{2}$ tension is gradually reduced by the utilization of $\mathrm{O}_{2}$ by the fruits and the $\mathrm{CO}_{2}$ tension is gradually increased by $\mathrm{CO}_{2}$ production, there is a depression of the respiration. In some

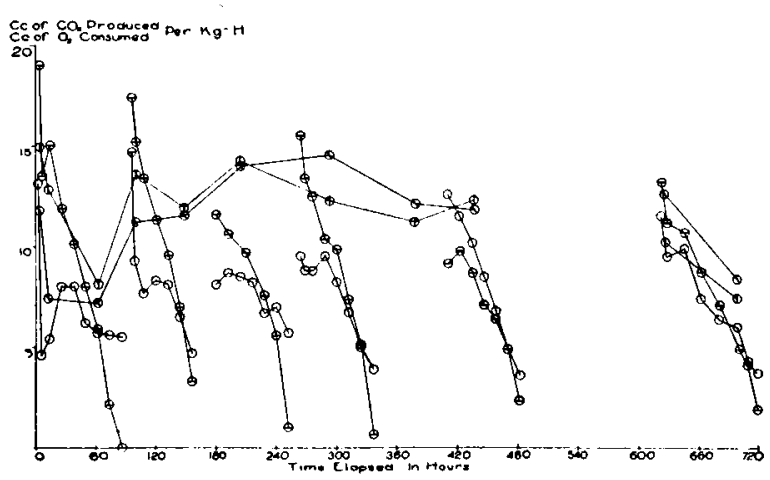

Figure 8. Respiratory activity of ripening fruits in a diminishing $\mathrm{O}_{2}$ supply followed by a replenishing of the air from which the $\mathrm{O}_{2}$ was again depleted. This alternation of depletion and replenishing was repeated five times during a period of one month. From the 340th to the 408th hour and again from the 484th to the 618th hour the fruits were exposed to normal air in the dark constant temperature room at $15-17^{\circ} \mathrm{C}$. During the remaining time the fruits were in a container closed except when the air was renewed. Plain circles represent the $\mathrm{CO}_{2}$ production and circles with horizontal lines the $\mathrm{O}_{2}$ consumption. It is to be noted that every time the air was renewed the respiration came back to the initial rate or even higher to be followed by a rapid decline, while the control, which is represented by circles with perpendicular lines for $\mathrm{CO}_{\mathrm{z}}$ production and circles with slanting lines for $\mathrm{O}_{2}$ consumption remain more nearly constant except during the early and final periods. During the early part the fruits were just beginning to ripen and at the end they were over-ripe. During the period when $\mathrm{O}_{2}$ tension was high in the container the $\mathrm{O}_{2}$ consumption was very much greater than the $\mathrm{CO}_{2}$ production but at the end of each cyc'e it was much less, denoting anaerobic respiration. 
fruits this depression is greater than in others. There seems to be no evidence that the $\mathrm{O}_{2}$ consumption begins to decrease while the $\mathrm{O}_{2}$ tension is still high, as was demonstrated by Chevillard for leaves of Hypnum triquetrum, potato tubers, and mushroom. The $\mathrm{O}_{2}$, consumption does, however, begin to decrease sooner and considerably more than the $\mathrm{CO}_{2}$ production. During the early part of the experiments considerably more $\mathrm{O}_{2}$ is consumed than $\mathrm{CO}_{2}$ produced. However, at some $\mathrm{O}_{2}$ tension or other this is reversed-more $\mathrm{CO}_{2}$ being produced than $\mathrm{O}_{2}$ consumed. Usually this happens when the $\mathrm{O}_{2}$ tension is about 2 per cent, but in the very young fruits it was found to occur at 3 to 4 per cent and in the ripening fruits at 7 per cent. The fact that oxygen consumption decreases sooner than the $\mathrm{CO}_{2}$ production, and finally becomes less, is evidence that anaerobic respiration may begin when the $\mathrm{O}_{2}$ tension is still quite high and gradually increases in amount until finally it alone is left. This phenomenon has previously been pointed out by the writer, and these experiments strengthen his previous contentions.

To determine the effect of this decrease of oxygen and increase of $\mathrm{CO}_{3}$ upon the permanent respiration of the fruits, several experiments were set up at $15^{\circ}$ to $18^{\circ} \mathrm{C}$. in which the air was renewed in the respiratory chamber whenever the $\mathrm{O}_{2}$ had become nearly exhausted.

In experiment 48 , which lasted one month, the air was renewed five times. When the experiment had continued twenty days the fruits were removed from the bottle but kept in the dark room for six days, when they were returned to the bottle and a new series of readings taken. A control of similar fruits was run at the same time. At the commencement of this experiment the fruits were pale green and the average size $5.4 \mathrm{~cm}$. in diameter. During the experiment the fruits ripened. This accounts for the rise in the respiration of the control, as has been shown in a previous publication (Gustafson, 1929).

In figure 8 the results are graphically illustrated. It is remarkable how the respiratory activity comes up to the initial rate or even higher every time the air is renewed and then decreases quite rapidly as the $\mathrm{O}_{2}$ tension is decreased and the $\mathrm{CO}_{2}$ increased. This is evidence enough that the fruits were not injured by the short periods of low $\mathrm{O}_{2}$ and high $\mathrm{CO}_{2}$ tensions. During the last period of the experiment the respiration of the control was decreasing. This was to be expected, as these fruits were somewhat riper than the experimental fruits, and, as has been previously shown, when the fruits are mature the $\mathrm{CO}$, production decreases. It may be pointed out here that, with a decrease in $\mathrm{O}_{2}$ and an increase in $\mathrm{CO}_{2}$ tension, the ripening process is slowed down, so that the experimental fruits were not quite so ripe as the controls. At the end of the experiment the fruits were in excellent condition. They had, however, lost some weight, no doubt mostly due to evaporation; the controls lost 8 per cent and the experimental fruits 4 per cent. The controls being on the shelves in the large temperature room would naturally lose more water. These experiments show that low $\mathrm{O}_{2}$ and high $\mathrm{CO}_{2}$ tensions, when lasting for only a short time, are not injurious to tomatoes but do retard the ripening processes.

\section{SUM MARY}

When tomatoes are exposed to a condition in which the $\mathrm{O}_{2}$ tension decreases and the $\mathrm{CO}$, tension increases, there is a concentration at which the respiratory activities are decreased, and the amount of decrease of respiration is associated with the stage of development of the fruits. The $\mathrm{O}_{2}$ and $\mathrm{CO}_{2}$ tensions at which this decrease occurs also vary with the stage of development. Short periods of exposure to low $\mathrm{O}_{2}$ and high $\mathrm{CO}$, tensions seem to be without injury to the fruits, but do retard ripening. The $\mathrm{O}_{2}$ consumption decreases earlier-i.e., at a higher $\mathrm{O}_{2}$ tension-than the CO, production. Although normally the $O_{2}$ consumption is somewhat greater than the $\mathrm{CO}$. production, yet there is an $\mathrm{O}_{2}$ and $\mathrm{CO}_{2}$ tension at which less $\mathrm{O}_{2}$ is consumed than $\mathrm{CO}_{2}$ produced. This may be assumed to be due to anaerobic resviration.

Department of Botany,

UNIVERSITY OF Michigan, An arbor, Michigan

\section{LITERATURE CITED}

Chevillard, I.. F. Hamon, A. Mayer, and L. Plantefal. 1930. Action de l'oxygène libre sur la respiration des tissus végétauxaeriens. Physicochim. Biol. 6: 464-505.

Gustafson, F. G. 1929. Growth studies on fruits. Respiration of tomato fruits. Plant Physiol. 4: 349356.

KIDD, F. 1916. The controlling influence of $\mathrm{CO}_{2}$. III. The retarding effect of $\mathrm{CO}_{2}$ on respiration. Proc. Roy. Soc. L London B 89: 136-156.

$\longrightarrow$, AND C. WEST. 1928, 1931, and 1933. Reports of the Food Investigation Board, London.

Novy, F. C., H. R. Roehm, ANd M. H. Soule. 1925. Microbic respiration. I. The compensation manometer and other means for the study of microbic respiration. Jour. Infect. Diseases 36: 109-167.

PariJa, P. 1928. Analytical studies in plant respiration. II. The respiration of apples in nitrogen and its relation to respiration in air. Proc. Roy. Soc. London B 103: 446-490.

Saxdo, C. E. 1920. The process of ripening in the tomato, considered especially from the commercial standpoint. U.S. Dept. Agr. Bulletin 859.

Stich, C. 1891. Die Athmung der Pflanzen bei verminderter sauerstoffspannung und bei Verletzungen. Flora 74: 1-57.

Willaman, J. J., And J. H. Beaumont. 1928. The effect of accumulated carbon dioxide on plant respiration. Plant Physiol. 3 : 45-59. 